\title{
Aphakic retinal detachment
}

\author{
R LE MESURIER, S VICKERS, S BOOTH-MASON, AND A H CHIGNELL
}

From the Ophthalmic Department, St Thomas's Hospital, London SE1 7EH

SUMmARY A study of 132 cases of aphakic retinal detachment (ARD) following mainly intracapsular cataract surgery has been made. Forty-nine cases $(37 \%)$ were found to have vitreous incarcerated into the cataract section out of a total of $54(41 \%)$ cases who had suffered a vitreous complication during cataract surgery. A study of the characteristics of ARD reveals that those cases having had a vitreous complication in the management of their cataracts are more likely to develop detachment within three months than those not suffering from such a complication. The occurrence of these early post-extraction retinal detachments is not influenced by the presence of underlying axial myopia. When we compared ARD in patients whose cataract extractions had been complicated by vitreous incarceration with those ARDs following uncomplicated cataract surgery, we found that the characteristics of the detachments were very similar. Thus distribution of underlying myopia, extent of detachment, length of time of detachment, and multiplicity and type of retinal holes were generally similar. However, ARD following complicated cataract surgery is more likely to suffer from periretinal fibrosis. The findings confirmed the risk of ARD following complicated intracapsular cataract surgery and support the tendency to perform the extracapsular operation.

The surgery of aphakic retinal detachment (ARD) has gained a reputation for difficulty because the retinal holes are often hard to find and, in comparison with phakic retinal detachment, ARD progresses more rapidly and has a more pronounced tendency to periretinal fibrosis. ${ }^{12}$ In most studies of ARD little attention has been paid to the coincident clinical findings in the anterior segment or to relate these findings to observations made in the posterior segment. In an attempt to reduce the incidence of ARD, the surgeon operating on the anterior segment has at times varied his approach to the removal of the crystalline lens. In extracapsular techniques in which surgery is followed by capsulotomy the incidence of ARD is not lower than in the intracapsular approach. ${ }^{34}$ However, recently there has been renewed interest in the methods of extracapsular extraction, and in techniques where the posterior capsule is preserved ARD is less likely to occur. ${ }^{-\infty}$

It is clear that changes in the anterior segment as a consequence to the cataract operation will be related to those subsequently occurring in the posterior segment. In this study we have tried to evaluate these events by studying both anterior and posterior segments in a group of patients suffering from ARD, Correspondence to Mr A H Chignell, FRCS. with particular emphasis on comparing ARD after uncomplicated extractions with ARD following complicated cataract extraction. We also studied for comparison a group of patients who underwent cataract surgery and who did not develop retinal detachment.

\section{Material and methods}

Two groups of patients were studied.

(1) $A R D$ group. One hundred and thirty-two consecutive cases of ARD seen in the Retinal Clinic at St Thomas's Hospital were examined. Information about these patients was gathered prospectively from proforma sheets filled in at the time of detachment surgery. Every patient was examined by indirect ophthalmoscopy and scleral depression with slit lamp biomicroscopy and three-mirror contact lens. Information was recorded on colour coded charts. Particular attention was paid to the cataract section using gonioscopy, noting the presence of not of vitreous in the anterior chamber and whether or not there was incarceration of vitreous into the cataract section. When possible, the records made at the time of cataract surgery were checked with particular regard to recorded vitreous loss. ARD cases subsequent to 
cataract surgery following trauma or following the surgery of congenital cataract surgery were excluded.

(2) Cataract group. The anterior segments of 200 eyes (146 patients) not complicated by subsequent retinal detachment were examined. These cases were as nearly consecutive as possible, exceptions being those patients who were unable to attend for examination. All these cases had their cataract surgery more than one year prior to the examination.

\section{Results}

\section{TYPE OF CATARACT EXTRACTION}

In both cataract and ARD groups there was a high incidence of intracapsular cataract extraction. In the ARD group of 132 eyes 126 had had intracapsular extraction and six had had extracapsular extractions. In the latter cases two subsequently had had a substantial posterior capsulotomy performed. In the cataract group 196 eyes had intracapsular operations and only four had extracapsular operations (none of these had had posterior capsulotomy).

\section{VITREOUS LOSS AND VITREOUS INCARCERATION}

$A R D$ group. Of 132 ARD cases $31(23 \%)$ suffered recorded vitreous loss at the time of cataract surgery. Of these 31 patients we found that only five had absence of vitreous from the cataract section. The remaining 26 were found to have a varying extent of vitreous incarceration into the cataract wound. We also found an additional 23 cases where vitreous was incaracerated into the section in spite of apparently uneventful cataract surgery. A total of 49 cases $(37 \%$ of the total ARD group) therefore had incarcerated vitreous into the section, which, with the additional five cases of recorded vitreous loss, where vitreous had been freed from the section, meant that a total of 54 ARD patients $(41 \%)$ had suffered a vitreous complication in their management.

Cataract group. In the group of 200 cases 17 were recorded as having lost vitreous at surgery. When we examined these 17 patients, seven were found to have vitreous incarceration into the section. A further 10 cases were found to have vitreous in the section after what was recorded as uncomplicated surgery. Thus of 200 cataract patients, an unexpectedly high number of 27 were found to have a vitreous complication in their management $(13.5 \%)$, and 17 of these still had vitreous in the section ( $8 \cdot 5 \%)$. It is well known that to leave vitreous incarcerated in the section at the end of surgery is undesirable, as an unacceptably high proportion of these cases fare badly. ${ }^{9}$ Our findings showed that, of the 17 patients in whom vitreous loss had been recorded, in only 10 was the clearance of vitreous from the wound adequate. In a further 10 cases vitreous incarceration into the wound was not recognised at all, though it is possible that in some cases vitreous may have become adherent to the cataract section in the postoperative period.

The cataract and the ARD group are not statistically comparable, but the difference in vitreous complications between the two groups suggests the importance of this event in promoting aphakic retinal detachment.

\section{CHARACTERISTICS OF THE ARD GROUP}

Sex. We confirmed the previously reported ${ }^{2310}$ proclivity for ARD to affect males. Out of 111 patients 69 were male and 42 were female.

Age. The ages in the ARD group ranged from 48-91 years with a peak incidence in the 60-70-year age group. These ranges were consistent with those of other studies. ${ }^{2}$

Refractive state. This was deduced by similar methods and definitions as those used by previous workers. ${ }^{51112}$

Myopia and vitreous complication. Of the 54 ARD patients who suffered a vitreous complication 19 (35\%) were previously myopic. In the 78 ARD cases that were not associated with a vitreous complication $37(49 \%)$ were myopic. Thus there was no tendency for the vitreous complication group to contain relatively more myopes.

We compared the characteristics of aphakic retinal detachments whose cataract extractions had been complicated by a vitreous event with those in which no such complication had occurred. We studied the interval between the cataract extraction and the presentation of the retinal detachment, the duration of the retinal detachment at the time of retinal surgery, the characteristics of the retinal holes, the extent of the detachment at the time of presentation, and the presence of periretinal fibrosis.

Interval between the cataract extraction and the onset of retinal detachment. Among the 54 ARD cases whose cataract extraction had been complicated by a vitreous complication $22(42 \%)$ detachments occurred within three months after extraction (we called this early ARD). Of the 78 patients with ARD whose cataract operation had not been complicated by vitreous event only $8(10 \%)$ suffered retinal detachment within three months of extraction. These findings (Figs. 1 and 2 ) show that the risk of early detachment significantly increases $(p<0.01)$ in those patients who have had a vitreous complication in their cataract surgery. This confirms the finding of a previous study. ${ }^{13}$

Underlying myopia and early ARD. In the 54 cases of ARD following complicated cataract extraction there were 19 with underlying myopia and 35 without underlying myopia. Among the latter 35 cases 14 $(39 \%)$ became detached within three months. Of the 


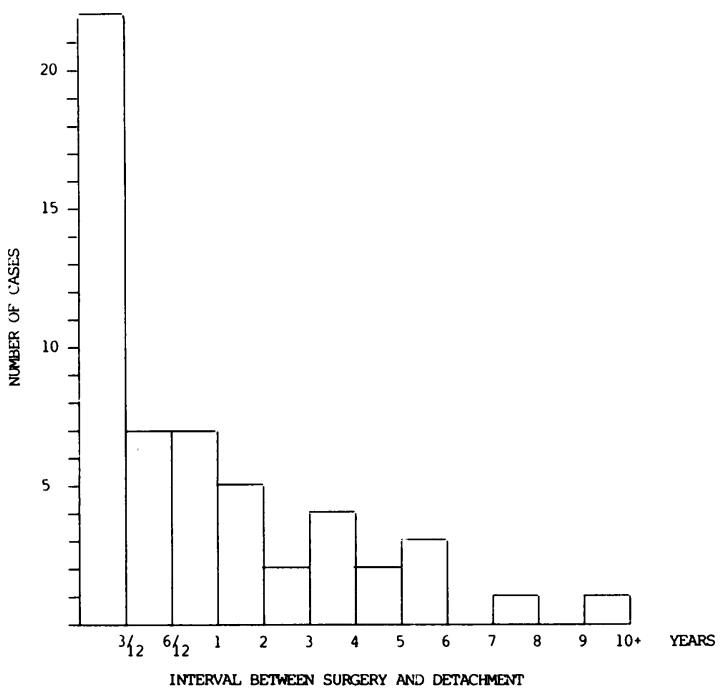

Fig. $1 A R D$ following complicated cataract surgery.

19 cases with underlying myopia eight ( $42 \%)$ became detached within a similar period. The difference between the two groups is not statistically significant $(p>0 \cdot 05)$ and shows that detachment within three months (early ARD) is not influenced by underlying myopia.

Extent of detachment. Table 1 shows that there was no difference in the extent of the detachment between those patients with ARD who suffered a vitreous complication in the management of their cataract extraction and those who had not suffered this complication ( $p>0.05)$.

Table 1 Extent of detachment at presentation in 132 ARDs

\begin{tabular}{|c|c|c|}
\hline Group & $\begin{array}{l}\text { 1-2 quadrants } \\
\text { detached }\end{array}$ & $\begin{array}{l}\text { More than } 2 \text { quadrants } \\
\text { detached }\end{array}$ \\
\hline \multicolumn{3}{|c|}{$\begin{array}{l}\text { ARD following complicated } \\
\text { cataract extraction } \\
\text { (54 eyes) }\end{array}$} \\
\hline $\begin{array}{l}\text { ARD following uncomplicate } \\
\text { cataract extraction }\end{array}$ & & \\
\hline (78 eyes) & $35(45 \%)$ & $43(55 \%)$ \\
\hline
\end{tabular}

Table 2 Duration of detachment at time of surgery in 132 ARDs

\begin{tabular}{lll}
\hline Group & Less than I month & More than 1 month \\
\hline $\begin{array}{l}\text { ARD following complicated } \\
\text { cataract extraction }\end{array}$ & \\
$\begin{array}{l}\text { (54 eyes) } \\
\text { ARD following uncomplicated }\end{array}$ & $30(56 \%)$ \\
$\begin{array}{l}\text { cataract extraction } \\
\text { (78 eyes) }\end{array}$ & $30(39 \%)$ & $48(61 \%)$ \\
\hline
\end{tabular}

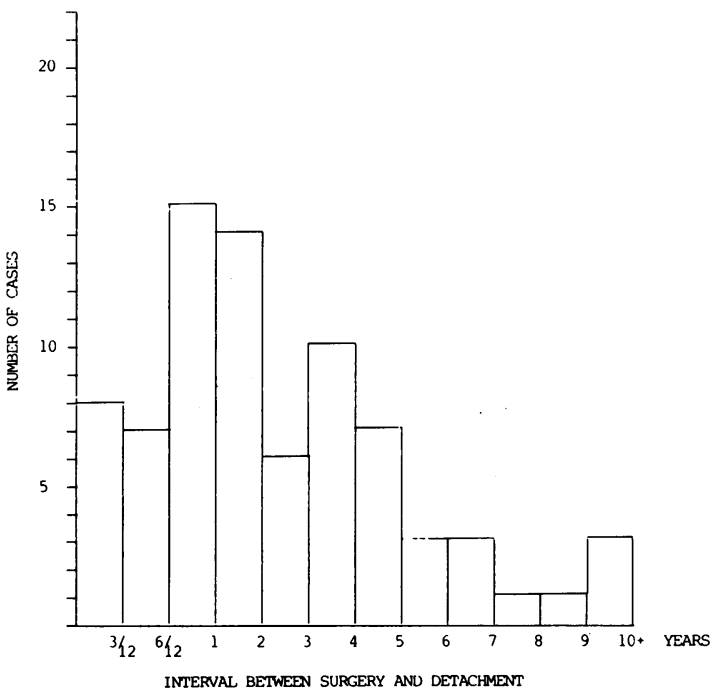

Fig. 2 ARD following uncomplicated cataract surgery.

Length of time of detachment. Table 2 shows that there was no difference between the length of time of detachment between those patients with ARD who suffered a vitreous complication during their cataract extraction and those who had not suffered this complication $(p>0.05)$.

\section{RETINAL HOLES}

Multiplicity of holes (Table 3). Among the cases of ARD following complicated cataract surgery there were 16 where the retinal holes were multiple. In only two of these were more than two holes found, and in no case was a retinal detachment characterised by a multiplicity of holes widely separated in detached retina. Among ARD cases following uncomplicated cataract surgery there were 23 with multiple holes. In 19 of them holes were found in one quadrant of the retina, and in only four were the holes widely separated. Thus even in uncomplicated ARD cases the so-called typical aphakic detachment ${ }^{14}$ is characterised by multiple holes was rarely seen. Failure to detect retinal holes was similar in the two groups.

Periretinal fibrosis. Periretinal fibrosis ranged in severity from early periretinal membrane formation to massive proliferative vitreoretinopathy and was

Table 3 Number of retinal holes

\begin{tabular}{llll}
\hline Group & Single & Multiple & Nil \\
\hline $\begin{array}{c}\text { ARD following complicated } \\
\text { cataract extraction (54 eyes) }\end{array}$ & $76(48 \%)$ & $16(30 \%)$ & $12(22 \%)$ \\
$\begin{array}{c}\text { ARD following uncomplicated } \\
\text { cataract extraction (78 eyes) }\end{array}$ & $35(45 \%)$ & $23(29 \%)$ & $20(26 \%)$ \\
\hline
\end{tabular}


Table 4 Results of surgery

\begin{tabular}{llr}
\hline & Success & Failure \\
\cline { 2 - 3 } & $114(86 \%)$ & $18(14 \%)$ \\
\hline $\begin{array}{c}\text { ARD following complicated } \\
\text { cataract extraction (54 eyes) }\end{array}$ & $46(85 \%)$ & $8(15 \%)$ \\
$\begin{array}{c}\text { ARD following uncomplicated } \\
\text { cataract extraction (78 eyes) }\end{array}$ & $68(87 \%)$ & $10(13 \%)$ \\
\hline
\end{tabular}

found in some degree in $51(39 \%)$ of the 132 ARD cases. Periretinal membranes were found to have formed in 32 of the 54 cases $(59 \%)$ of ARD whose cataract had been associated with vitreous complications. But they were found in only 19 out of 78 cases $(24 \%)$ of ARD whose cataract extractions had been uncomplicated. This difference is significant $(p<0.01)$. It should be noted that we had found that the length of time of the detachment (a factor contributing to periretinal fibrosis) was not significantly different between the two groups (Table 2). Thus cases of ARD associated with periretinal membranes are more likely to occur if the ARD had followed a complicated cataract operation.

\section{RESULTS OF SURGERY}

Successful treatment was defined as achievement of a flat retina, and the shortest follow-up period has been one year. This was obtained in 114 cases $(86 \%)$, as seen in Table 4. It can be seen that the anatomical results of surgery in both groups of ARD are almost identical.

\section{Discussion}

Even though we found vitreous adherent to the cataract section in $8.67 \%$ of cases of cataract operations not complicated by subsequent retinal detachment, the finding that 49 cases $(37 \%)$ of our total series of 132 ARDs had vitreous incarcerated into the section, and that $54(41 \%)$ cases had suffered a vitreous complication during the management of their cataract surgery, confirms that this is a complication of importance in promoting events leading to subsequent retinal detachment. Forward movement of gel following intracapsular lens extraction to fill the space previously occupied by the lens not only encourages posterior vitreous detachment if not already present at the time of surgery ${ }^{1016} 17$ but, by filling the space previously occupied by the crystalline lens, effectively increases the volume of the vitreous cavity and results in increased capacity for excursion of the gel when it moves. This in turn results in greater dynamic traction ${ }^{18}$ at the posterior border of the vitreous base following vitreous detachment than exists in the phakic eye. Our findings indicate that incarceration of gel into the cataract section greatly increases the risk of retinal detachment in the aphakic eye following intracapsular extraction. It seems that this anterior incarceration alters the nature of the posterior vitreous detachment, tending to increase dynamic traction at the posterior border of the vitreous base in these cases. We were somewhat surprised to find there was little difference in the morphological characteristics of the type of retinal detachment in those aphakic retinal detachments following cataract surgery associated with vitreous complications and those following uncomplicated cataract surgery. Thus there was similarity in the extent of the detachment, the duration of the retinal detachment, and the type and position of the retinal holes, but there was a greater tendency to early detachment and to periretinal membrane formation in ARD following cataract surgery associated with vitreous complication.

The pathogenesis of ARD following intracapsular cataract surgery is probably multifactorial, and our concentration on vitreous events in the anterior segment does not discount the importance of other associated factors that may be contributing-for example, myopia and lattice degeneration. Unlike these other factors, however, the removal of cataract is under surgical control, and this study indicates that the intracapsular cataract operation carrying with it the risk of vitreous complications strongly predisposes the eye to early ARD if these complications occur. We do not have enough information to know if proper management of vitreous loss by removing vitreous from the section will reduce the risk of aphakic detachment in these cases.

This study gives weight to the growing popularity of extracapsular cataract surgery, which preserves the integrity of the posterior segment.

We are grateful to Mrs Margaret Grice and Miss Louise Grocot for their secretarial assistance.

This study was in part supported by the Iris Fund.

\section{References}

1 Norton EWD. Retinal detachment in aphakia. Am J Ophthalmol 1964; 58: 111-24.

2 Ashrafzadeth MT, Schepens CL, Elzeneiny II, Moura R, Morse OH, Kraushar MF. Aphakic and phakic retinal detachment. Arch Ophthalmol 1973; 89: 476-83.

3 Shapland CD. Retinal detachment in aphakia. Trans Ophthalmol Soc UK 1934; 54: 176-92.

4 Wilkinson CP, Anderson LS, Little JH. Retinal detachment following phakoemulsification. Ophthalmology (Rochester) 1978; 85: 151-6.

5 Percival SB, Anand V, Das SK. Prevalence of aphakic retinal detachment. Br J Ophthalmol 1983; 67: 43-5.

6 Wetzig PC, Thatcher DB, Christianson JM. The intracapsular versus the extracapsular cataract technique in relationship to retinal problems. Trans Am Ophthalmol Soc 1979; 77: 339-47. 
7 Hurite FG, Sorr EM, Everett WG. The incidence of retinal detachment following phakoemulsification. Ophthalmology (Rochester) 1978; 86: 2004-6.

8 Wise JB. Retinal detachment after phacoemulsification. Ophthalmology (Rochester) 1979; 86: 2007-10.

9 Vail D. After-results of vitreous loss. Am J Ophthalmol 1965; 5: 573-86.

10 Bagley CH. Retinal detachment: Survey of etiology and results of treatment in phakics and aphakics. Am J Ophthalmol 1948; 31: 285-98.

11 Hyams SW, Bialik M, Neuman E. Myopia-aphakia prevalence of retinal detachment. BrJ Ophthalmol 1975; 59: 480-2.

12 Ruben M, Rajpurdhit P. Distribution of myopia in aphakic retinal detachment. Br J Ophthalmol 1976; 60: 517-21.
13 Gilbert CE, Lamb RJ, Martin B. Aphakic retinal detachment -prophylaxis in the second eye. Trans Ophthalmol Soc UK 1983; 103: 161-4.

14 Schepens CL. Retinal detachment. Philadelphia: Saunders, 1983: 2: 639-40.

15 Phillips CI. Distribution of breaks in aphakic and senile eyes with retinal detachment. Br J Ophthalmol 1963; 47: 744-52.

16 Rosen E. Vitreous detachment associated with nuclear sclerosis. Am J Ophthalmol 1962; 54: 837-41.

17 Foos RT. Posterior vitreous detachment. Ophthalmology (Rochester) 1972; 76: 480-97.

18 Scott JD. Static and dynamic vitreous traction. Trans Ophthalmol Soc UK 1971; 91: 175-88. 